\title{
Household Food Insecurity and Unavailability of Toilet Facility Contribute to Adverse Health Outcomes of Under-five Children in Bangladesh: A Cross-sectional Study
}

Mohammad Ashraful Islam

International Centre for Diarrhoeal Disease Research

Mahfuzur Rahman

International Centre for Diarrhoeal Disease Research

Md. Fakhar Uddin

International Centre for Diarrhoeal Disease Research

Md. Tariqujjaman

International Centre for Diarrhoeal Disease Research

Gobinda Karmakar

International Centre for Diarrhoeal Disease Research

Mohammad Ashikur Rahman

BRAC

Matthew Kelly

The Australian National University

Darren Gray

The Australian National University

Tahmeed Ahmed

International Centre for Diarrhoeal Disease Research

Haribondhu Sarma ( $\nabla$ haribondhu.sarma@anu.edu.au )

The Australian National University

\section{Research Article}

Keywords: Household food insecurity, Sanitation, Under-five children, Bangladesh

Posted Date: September 16th, 2021

DOI: https://doi.org/10.21203/rs.3.rs-860418/v1

License: (c) (i) This work is licensed under a Creative Commons Attribution 4.0 International License. Read Full License 
Page $2 / 21$ 


\section{Abstract}

\section{Background}

Despite recent progress in rural economic development and food production, the prevalence of household food insecurity (FI) and use of unimproved toilet facilities are widespread in Bangladesh. Limited studies have sought to understand the relationship of household FI and sanitation, separately and in combination, with child morbidity. This paper aimed to assess the effect of Fl and unimproved toilet facility of households on adverse health outcomes of children less than five years of age in Bangladesh.

\section{Methods}

We used data from a cross-sectional survey that was conducted as part of an evaluation of the Maternal, Infant and Young Child Nutrition (MIYCN) Program in Bangladesh. The study population included children aged 6-59 months and their caregivers, identified using a two-stage cluster-sampling procedure. Child morbidity status was the outcome variable, and household FI status and type of toilet used were considered the main exposure variables in this study. We performed logistic regression, calculated adjusted odds ratios (AOR) to assess the association of child morbidity with household FI and unimproved toilet facility after adjusting for potential confounders.

\section{Results}

A total of 1,728 households were eligible for this analysis. About $23 \%$ of the households were foodinsecure, and a large number of households had improved toilet facilities (93.4\%). In the multivariable logistic regression model, we found that children in food-insecure households with unimproved toilet facility had 5.88 (AOR: $5.88 ; 95 \% \mathrm{Cl} 2.52,13.70$ ) times more chance, of being morbid compared to the children of food-secure households with improved toilet facility. A similar association of $\mathrm{Fl}$ and toilet facilities with each of the morbidity components was observed, including diarrhea (AOR:3.6; 95\% Cl 1.79, 7.89), fever (AOR:3.47; 95\% Cl 1.72, 6.99), difficult or fast breathing with cough (AOR:3.88; 95\% Cl 1.99, 7.59), and difficult or fast breathing with blocked or running nose (AOR:1.29; 95\% $\mathrm{Cl} 0.56,2.95)$.

\section{Conclusions}

Our study shows that household FI and unimproved toilet facility jointly have more deteriorative effects on child morbidity than either of these conditions alone. Therefore, it is important to consider these two critical factors while designing a public health intervention for reducing morbidity among under-five children.

\section{Background}

Household food insecurity (FI) is a measure of the availability of food in households and lack of access to an adequate amount of safe and nutritious food to fulfill dietary requirements for an active and healthy life [1]. Fl is a multi-dimensional phenomenon that occurs in most countries at all income levels [2], 
globally 795 million people remain food-insecure [3]. In 2017, the prevalence of experiencing severe $\mathrm{FI}$ was estimated at $27.4 \%$ in Africa, $7 \%$ in Asia, $6.4 \%$ in Latin America, and 1.2\% in North America [3]. In Bangladesh about 25\% of the population remained FI in 2019 [4], despite the country making some progress in achieving food self-sufficiency through agricultural improvement, food production, as well as reducing under-five mortality [5]. According to the Global Food Security Index 2017, Bangladesh was ranked 89th out of 113 countries for prevalence of food insecurity [5].

Previous studies have identified several adverse consequences of household FI among infants and young children [6], including long-term impacts on children's health [7]. Studies conducted in low-income settings [6-10] observed significant associations between household FI and childhood illness. For example, a study in Ethiopia observed household $\mathrm{FI}$ as a significant risk factor for increasing morbidity. Fl increased the risk of childhood diarrhea 1.44 times, cough 1.42 times and fever 1.53 times compared to children in food-secure households [8]. Children in FI households are also at risk of poor development, impaired performance in school and depression and poor health in adulthood, and are more likely to be stunted and suffer from undernutrition [11-13].

As well, measuring $\mathrm{Fl}$ alone may not be sufficient in assessing child morbidity-outcome risks if the other major driver of such morbidity, in terms of sanitation, is not considered [14]. Despite consistent improvement in rural economic development in Bangladesh, national survey data shows $57 \%$ of households were using unimproved toilet facilities in 2017 [15]. The effect of unimproved toilet facilities on child undernutrition and childhood morbidity have been well established $[16,17]$. A study conducted in rural northern Bangladesh observed that the use of unimproved toilet facilities increased the risk of childhood acute respiratory infection by $31 \%$ [18]. A study in India showed that access to an improved toilet can reduce childhood diarrhea by more than $2 \%$ [17]. Another recent study conducted in Myanmar observed children in the household with unimproved toilet facility were at significantly higher risk of suffering from cough and fever compared to households with improved toilets [19].

Although numerous studies have assessed adverse childhood health outcomes of household $\mathrm{FI}$ and unimproved toilet facilities, to our knowledge, no study has measured the combined effect of household $\mathrm{Fl}$ and unimproved toilet facility on the morbidity status of children. This paper aimed to assess the effect of FI and unimproved toilet facility of households on adverse health outcomes of children less than five years of age in Bangladesh. We expect that the findings of this study will inform the development of programs to improve child health outcomes through consideration of combinations of risk factors.

\section{Methods}

\section{Data source}

In this paper, we used the data from a cross-sectional survey that was conducted as part of an evaluation of the Maternal, Infant and Young Child Nutrition (MIYCN) Program of BRAC (formerly known as 
Bangladesh Rural Advancement Committee), an international non-governmental organization based in Bangladesh. Data was collected during April-May 2016.

\section{Study area}

The study area comprised nine districts of Bangladesh where BRAC was implementing its MIYCN program (Fig. 1). BRAC has selected these districts considering the availability BRAC programme-delivery infrastructures including the availability of its community health workers who were trained to implement the MIYCN interventions at the community level.

\section{Study population}

The study population included children aged 6-59 months and their caregivers. The caregiver was defined as the child's biological mother or the person who takes care of or looks after and gives the child most meals on most days in the past seven days before the survey. Inclusion criteria allowed selection of the households of caregivers who had at least one child of 6-59 months and where the caregivers had resided in that household for at least one year. We excluded households if the caregiver was unable to attend an interview during the day of the survey due to illness or was unable to give consent to participate in the survey. If the household has more than one eligible child, we randomly selected one child for the survey.

\section{Sample-size and sampling}

We calculated sample-size for a district-level estimation; we considered $50 \%$ prevalence, the precision of $\pm 10 \%$, Za value of 1.96 , and a design effect of 2 . The use of the standard sample-size calculation formula yielded the minimum sample-size of 192 households per district. Thus, the total sample-size was 1,728 .

We followed the two-stage cluster-sampling procedure. In the first stage, systematic random- sampling procedure was applied to select 16 Primary Sampling Units (PSUs) from the complete list of BRAC communities in a district. This procedure helped to ensure the equal chance of being included in the sample, and the resulting sample was close to an even spatial sample of BRAC's target areas. In the second stage, the survey team ensured the population-size, total approximate households, and the boundaries of the PSU on arrival at the selected PSU and in consultation with and assistance of the local people (Union Parishad Chairman, Member, Counselor, school teacher, elderly person, and the relevant personnel of the locality). A physical map-segment sample approach was exercised to segment the selected community or PSU. The detailed sampling procedures have been reported elsewhere [20].

\section{Outcome variable}

Child morbidity status was the outcome variable for this study. We considered children to be experiencing morbidity if their caregivers reported that their child had been sick either due to ailments, such as diarrhea (diarrhea with 3 or more loose or watery, bloody, pussy or mucous stools in a 24 hour period), fever (illness with fever), illness with cough and had difficulty in breathing or fast breathing, difficult or fast breathing with blocked or runny nose in the last 14 days before the survey. In addition to the caregivers 
recall, we also collected child's morbidity related information from the doctor's prescriptions/medicines if the child received any treatment from a doctor during the last episode of illness. If caregivers reported any of the illnesses being present in their child, or if medical records indicated a sickness episode, then we considered them as experiencing morbidity.

\section{Exposure variable and covariates}

Household FI status (categorized as food-insecure, food-secure) was considered the main exposure variable in this study. We assessed households FI status based on 9 questions from the Household Food Insecurity Access Scale (HFIAS) developed by the Food and Nutrition Technical Assistance (FANTA) group in collaboration with Tufts University and Cornell University [21]. The response to each question ranges from 0 to 30 . We made scoring of these responses as $0=0,1-2=1,3-10=2$, and $11-30=3$. The total score ranged from 0 to 27 for 9 questions. We then categorized as score $0-1=$ food-secure household and 2-27 = food-insecure household. Other exposure variables included toilet availability, categorized as: Improved toilet (flush or pour flush to a piped sewer system, septic tank, pit latrine, Kumasi Ventilated Improved Pit latrine, pit latrine with slab), unimproved toilet (pit latrine without a slab, hanging latrine or defecate in bush or field). We also combined food security and toilet facilities of households to see the combined effects in regression analysis and we categorized them as: Food-secure and improved toilet, Food-secure and unimproved toilet, Food-insecure and improved toilet, Food-insecure and unimproved toilet.

Other covariates included household-size (categorized as: $<5, \geq 5$ ), number of $6-59$ months old children in the household (categorized as: one, two, or more), child's age (6-23 months, 24-59 months), any children in the household aged 5-14 year who were attending school, caregiver's age ( $<25$ years, $\geq 25$ years), caregiver's education ( $<5$ years, $\geq 5$ years), father's age (categorized as: $<30$ years, $\geq 30$ years), caregiver's religion (categorized as: Muslim, Hindu/Other religion), caregiver's occupation (categorized as: other, housewife), wealth index (categorized as: poor, middle, rich), and monthly household income [categorized as: $<11000$ BDT (Bangladeshi taka), $\geq 11000$ BDT (83 BDT = 1 USD)].

\section{Data collection}

We measured the level of anxiety and uncertainty of the participants about household food supply, insufficient quality of food, and insufficient food intake by following the HFIAS that comprises a brief survey instrument to assess whether households have experienced problems with accessing food during the last 30 days of survey. The questionnaire used a nine-item household hunger scale questionnaire [(i) worry about food, (ii) unable to eat preferred foods, (iii) eat just a few kinds of foods, (iv) eat foods they really do not want to eat, (v) eat a smaller meal, (vi) eat fewer meals in a day, (vii) no food of any kind in the household, (viii) go to sleep hungry, and (ix) go a whole day and night without eating)].

Before finalizing the questionnaire, a field test was conducted in a real-field setting in the non-survey areas, and the feedback from the field test was incorporated into the final version of the questionnaire. It was then submitted to the Institutional Review Board (IRB) of icddr,b for review and approval. A Standard Operating Procedure (SOP) was developed for the interviewers. This SOP was a guide for the interviewers 
on how to ask each of the questions to the participants. The electronic data-collection procedures used an Android-based Smartphone program of survey questionnaire. To support the Android operating system, Open Data Kit (ODK) software was used for developing the program. TABs/Smartphones were used and both Bangla and English versions questionnaire were used in the ODK software.

\section{Data analysis}

Weighted and cluster (PSU)-adjusted descriptive statistics were estimated and presented in percentages with respective $95 \%$ confidence intervals. Bivariate analysis using a chi-square test was performed to measure the association between the outcome variable (morbidity status of the children) and main exposure variables (household FI and toilet facilities). We performed multivariable logistic regression analysis to measure the association between outcome variables and other independent variables. At first, we performed unadjusted logistic regression to find the significant variables for the final multivariable regression model; $\mathrm{p}$-value of $<0.05$ was considered for the significance level. Finally, multivariable logistic regression was performed to assess the association of child morbidity with household $\mathrm{FI}$ and unimproved toilet facility after adjusting for potential confounders and presented in adjusted odds ratios with a $95 \%$ confidence interval. All analyses were performed using statistical software STATA (Version 13).

\section{Results}

Socio-demographic and background characteristics of the study participants have been presented in Table 1. A total of 1,728 households were eligible for this analysis. Around $61 \%$ of households had $\geq 5$ members, and about $85 \%$ had one child aged 6-59 months of age. Most of the selected respondents were biological mothers (97\%) of the eligible children. Caregivers aged $>25$ years were $55 \%$, and $76.2 \%$ of the caregivers had completed $\geq 5$ years of schooling. About $68 \%$ of fathers of the eligible children completed five or more years of schooling. 
Table 1

Socio-demographic and background characteristics of the study participants

\begin{tabular}{|c|c|c|}
\hline Indicator & \multicolumn{2}{|l|}{$\%(n)$} \\
\hline \multicolumn{3}{|c|}{ Household members } \\
\hline$<5$ & $39.4(680)$ & $36.6-42.2$ \\
\hline$\geq 5$ & $60.6(1048)$ & $57.8-63.4$ \\
\hline \multicolumn{3}{|c|}{ Age (years) of mother/caregiver } \\
\hline$\leq 25$ years & $45.1(805)$ & $42.4-47.8$ \\
\hline$>25$ years & $54.9(923)$ & $52.2-57.6$ \\
\hline \multicolumn{3}{|c|}{ Mother's/Caregiver's with $\geq 5$ years of education } \\
\hline No & 23.9 (399) & $21.3-26.6$ \\
\hline Yes & $76.2(1329)$ & $73.4-78.7$ \\
\hline \multicolumn{3}{|c|}{ Religion of respondents } \\
\hline Hindu and other & $8.3(174)$ & $5.6-12.0$ \\
\hline Muslim & $91.7(1554)$ & $88.0-94.4$ \\
\hline \multicolumn{3}{|c|}{ Most recent birth of caregiver } \\
\hline$>12$ months & $83.4(1438)$ & $81.2-85.4$ \\
\hline$\leq 12$ months & $16.6(290)$ & $14.6-18.8$ \\
\hline \multicolumn{3}{|c|}{ Working status of caregiver } \\
\hline Other & $6.3(106)$ & $5.0-7.9$ \\
\hline Housewife & $93.7(1622)$ & $92.1-95.0$ \\
\hline \multicolumn{3}{|c|}{ Age (years) of fathers } \\
\hline$\leq 30$ years & $41.1(714)$ & $38.3-43.9$ \\
\hline >30 years & 58.9 (999) & $56.1-61.6$ \\
\hline \multicolumn{3}{|c|}{ Fathers with $\geq 5$ years of education } \\
\hline No & $32.3(543)$ & $29.2-35.5$ \\
\hline Yes & $67.8(1185)$ & $64.5-70.8$ \\
\hline *1 USD = $83 \mathrm{BDT}$ & & \\
\hline
\end{tabular}




\begin{tabular}{|c|c|c|}
\hline Indicator & $\%(n)$ & $95 \% \mathrm{Cl}$ \\
\hline \multicolumn{3}{|c|}{ Age categories of child (in months) } \\
\hline $6-23$ months & $39.7(685)$ & $37.2-42.3$ \\
\hline $24-59$ months & $60.3(1043)$ & $57.7-62.8$ \\
\hline \multicolumn{3}{|l|}{ Sex of children } \\
\hline Female & $47.0(822)$ & $44.2-49.8$ \\
\hline Male & $53.0(906)$ & $50.3-55.8$ \\
\hline \multicolumn{3}{|c|}{ Children aged 5-14 years attending school } \\
\hline No & $2.9(28)$ & $1.8-4.8$ \\
\hline Yes & $97.1(1097)$ & $95.2-98.2$ \\
\hline \multicolumn{3}{|c|}{ Number of children 6-59 months } \\
\hline One & $85.3(1477)$ & $83.0-87.4$ \\
\hline Two and above & $14.7(251)$ & $12.6-17.0$ \\
\hline \multicolumn{3}{|l|}{ Morbidity status } \\
\hline No & $44.0(782)$ & $41.4-46.7$ \\
\hline Yes & $56.0(946)$ & $53.3-58.6$ \\
\hline \multicolumn{3}{|l|}{ Food security status } \\
\hline Food-insecure household & $23.1(387)$ & $20.4-26.0$ \\
\hline Food-secure household & $76.9(1341)$ & $74.0-79.6$ \\
\hline \multicolumn{3}{|c|}{ Toilet facilities of household } \\
\hline Improved toilet & $93.4(1602)$ & $91.2-95.0$ \\
\hline Unimproved toilet & $6.6(126)$ & $5.0-8.8$ \\
\hline \multicolumn{3}{|l|}{ Wealth Index } \\
\hline Poor & $21.2(345)$ & $18.0-24.8$ \\
\hline Middle & $40.4(705)$ & $37.0-43.8$ \\
\hline Rich & 38.5 (678) & $34.3-42.8$ \\
\hline \multicolumn{3}{|l|}{ Income of household } \\
\hline *1 USD = 83 BDT & & \\
\hline
\end{tabular}




\begin{tabular}{|lll|}
\hline Indicator & $\begin{array}{l}\mathbf{N}=1,728 \\
\%(n)\end{array}$ & $95 \%$ Cl \\
\hline <BDT 11000* & $53.2(926)$ & $50.2-56.1$ \\
\hline$\geq$ BDT 11000 & $46.8(802)$ & $43.9-49.8$ \\
\hline *1 USD = 83 BDT & & \\
\hline
\end{tabular}

Sixty percent of the children belonged to the age-group of 24-59 months. Around $97 \%$ of the children aged 5 to 14 years were attending school. The ratio of boys and girls was 53:47. Fifty-six percent of caregivers of under- 5 children reported that their children had been sick in the last two weeks prior to the day of the interview. Results showed that about $23 \%$ of the households were food-insecure, and a large number of households had improved toilet facilities (93.4\%).

Table 2 presents the association of morbidity status with food security and toilet facility status of the households. There was a significant $(p<0.001)$ association between morbidity status and either FI or unimproved toilet facility in the household. In food-secure households, $52.8 \%$ of children were found with morbidity but, in food-insecure households, child morbidity prevailed among $66.5 \%$ of households $(\mathrm{p}<$ 0.001). About $55 \%$ of children from households that had improved toilet facility had morbidity whereas this figure was about $75 \%$ in the households that had unimproved toilet facilities $(p<0.001)$. In the unadjusted logistic regression model, we found that the children of food-insecure households had $77 \%$ (OR: $1.77 ; 95 \% \mathrm{Cl} 1.27-2.47$ ) more likelihood of being morbid compared to children of food-secure households. Children of households with unimproved toilet facilities had 2.44 (OR: 2.44; 95\% Cl 1.464.06) times higher chances to be morbid compared to children of households with improved toilet facilities (Table 2). 
Table 2

Association between household food security and availability of toilet facilities and morbidity status of children who participated in the study

\begin{tabular}{|c|c|c|c|c|c|c|c|}
\hline \multirow[t]{3}{*}{ Indicator } & \multicolumn{2}{|c|}{ Any morbidity } & \multirow{3}{*}{$\begin{array}{l}\text { p- } \\
\text { value }\end{array}$} & \multirow[t]{3}{*}{ OR } & \multirow[t]{3}{*}{$95 \% \mathrm{Cl}$} & \multirow[t]{3}{*}{ AOR' } & \multirow[t]{3}{*}{$95 \% \mathrm{Cl}$} \\
\hline & Yes, & No, & & & & & \\
\hline & $\mathrm{n}(\%)$ & $\mathrm{n}(\%)$ & & & & & \\
\hline \multicolumn{8}{|c|}{ Food security status } \\
\hline Secure & $\begin{array}{l}52.8 \\
(693)\end{array}$ & $\begin{array}{l}47.2 \\
(648)\end{array}$ & \multirow[t]{2}{*}{$<.001$} & 1 & & \multicolumn{2}{|l|}{1} \\
\hline Insecure & $\begin{array}{l}66.5 \\
(253)\end{array}$ & $\begin{array}{l}33.5 \\
(134)\end{array}$ & & $1.77^{\star \star \star}$ & $\begin{array}{l}1.27- \\
2.47\end{array}$ & $1.60 * \star \star$ & $\begin{array}{l}1.15- \\
2.22\end{array}$ \\
\hline \multicolumn{8}{|l|}{ Toilets facilities } \\
\hline $\begin{array}{l}\text { Improved toilet } \\
\text { facilities }\end{array}$ & $\begin{array}{l}54.6 \\
(858)\end{array}$ & $\begin{array}{l}45.4 \\
(744)\end{array}$ & \multirow[t]{3}{*}{$<.001$} & 1 & & \multicolumn{2}{|l|}{1} \\
\hline $\begin{array}{l}\text { Unimproved } \\
\text { toilet }\end{array}$ & $74.6(88)$ & $25.4(38)$ & & $2.44^{\star \star \star}$ & $\begin{array}{l}1.46- \\
4.06\end{array}$ & $2.08^{\star \star \star}$ & $\begin{array}{l}1.24- \\
3.48\end{array}$ \\
\hline \multicolumn{7}{|l|}{ facilities } & \\
\hline \multicolumn{8}{|c|}{$\begin{array}{l}\text { 'The model adjusted by caregiver's education, caregiver's religion, number of children aged 6-59 } \\
\text { months, and household income }{ }^{\star} p<0.05, * \star p<0.01, * \star \star p<0.001 \text { (using Z- test). }\end{array}$} \\
\hline \multicolumn{8}{|c|}{$\begin{array}{l}\text { Chi-square test reported row percentage ( } p \text {-values of less than } 0.05 \text { were regarded as statistically } \\
\text { significant). }\end{array}$} \\
\hline
\end{tabular}

In multivariable logistic regression, we adjusted the model with caregiver's education, caregiver's religion, number of children aged 6-59 months in the household, household income, household food security status, and toilet facility of the household; it was found that children of food-insecure households were $60 \%$ (AOR: $1.60 ; 95 \% \mathrm{Cl} 1.15,2.22$ ) more likely to be morbid compared to children of food-secure households (Table 2). Furthermore, children of households with unimproved toilet facilities had 2.08 (AOR: $2.08 ; 95 \% \mathrm{Cl}: 1.24,3.48$ ) times higher likelihood of being morbid compared to children of households with improved toilet facilities (Table 2). 
Table 3

Factors associated with morbidity status of children who participated in the study

\begin{tabular}{|c|c|c|c|c|}
\hline Independent variable & OR & $95 \% \mathrm{Cl}$ & $\mathrm{AOR}^{9}$ & $95 \% \mathrm{Cl}$ \\
\hline \multicolumn{5}{|l|}{ Household members } \\
\hline$<5$ & 1 & & & \\
\hline$\geq 5$ & 0.94 & $0.74-1.19$ & & \\
\hline \multicolumn{5}{|c|}{ Age (years) of mothers/caregiver } \\
\hline$\leq 25$ years & 1 & & & \\
\hline$>25$ years & 1.17 & $0.95-1.44$ & & \\
\hline \multicolumn{5}{|c|}{ Mothers/Caregivers with $\geq 5$ years of education } \\
\hline No & 1 & & & \\
\hline Yes & 0.79 & $0.60-1.04$ & & \\
\hline \multicolumn{5}{|c|}{ Religion of respondents } \\
\hline Hindu and other & 1 & & & \\
\hline Muslim & 1.43 & $0.94-2.17$ & & \\
\hline \multicolumn{5}{|c|}{ Most recent birth of caregiver } \\
\hline$>12$ months & 1 & & & \\
\hline$\leq 12$ months & 1.25 & $0.93-1.69$ & & \\
\hline \multicolumn{5}{|c|}{ Working status of caregiver } \\
\hline Other & 1 & & & \\
\hline Housewife & 0.92 & $0.57-1.47$ & & \\
\hline \multicolumn{5}{|l|}{ Age (years) of father } \\
\hline$\leq 30$ years & 1 & & & \\
\hline$>30$ years & 1.13 & $0.92-1.40$ & & \\
\hline \multicolumn{5}{|c|}{ Father with $\geq 5$ years of education } \\
\hline No & 1 & & & \\
\hline Yes & 0.88 & $0.70-1.11$ & & \\
\hline \multicolumn{5}{|c|}{ Category of child's age (in months) } \\
\hline $6-23$ months & 1 & & 1 & \\
\hline 24-59 months & $0.73^{\star}$ & $0.57-0.93$ & $0.70 * \star$ & $0.55-0.90$ \\
\hline
\end{tabular}




\begin{tabular}{|c|c|c|c|c|}
\hline Independent variable & OR & $95 \% \mathrm{Cl}$ & AOR' & $95 \% \mathrm{Cl}$ \\
\hline \multicolumn{5}{|l|}{ Sex of child } \\
\hline Female & 1 & & & \\
\hline Male & 1.08 & $0.85-1.37$ & & \\
\hline \multicolumn{5}{|c|}{ Children aged 5-14 years attending school } \\
\hline No & 1 & & & \\
\hline Yes & 0.82 & $0.39-1.72$ & & \\
\hline \multicolumn{5}{|l|}{ Number of children aged 6-59 months } \\
\hline One & 1 & & & \\
\hline Two and above & 1.34 & $0.94-1.92$ & & \\
\hline \multicolumn{5}{|l|}{ Wealth Index } \\
\hline Poor & 1 & & & \\
\hline Middle & 1.22 & $0.96-1.56$ & & \\
\hline Rich & 1.20 & $0.89-1.61$ & & \\
\hline \multicolumn{5}{|l|}{ Income of household } \\
\hline$<$ BDT11000 & 1 & & 1 & \\
\hline$\geq$ BDT 11000 & $0.77 *$ & $0.62-0.96$ & 0.89 & $0.72-1.10$ \\
\hline \multicolumn{5}{|c|}{ Combined food security and toilet facilities of households } \\
\hline Food-secure and improved toilet & 1 & & 1 & \\
\hline Food-secure and unimproved toilet & 1.48 & $0.81-2.73$ & 1.49 & $0.79-2.83$ \\
\hline Food-insecure and improved toilet & $1.55^{\star}$ & $1.11-2.16$ & $1.53^{\star}$ & $1.09-2.15$ \\
\hline Food-insecure and unimproved toilet & 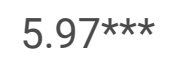 & $2.66-13.37$ & $5.88^{\star \star \star}$ & $2.52-13.70$ \\
\hline${ }^{\star} \mathrm{p}<0.05,{ }^{* \star} \mathrm{p}<0.01,{ }^{* \star *} \mathrm{p}<0.001$ & & & & \\
\hline
\end{tabular}

The simple and multivariable logistic regression model to explore the associated factors of morbidity status is presented in Table 3. In the unadjusted logistic regression model, we found age of children, household income, and combination of food security and toilet facility to be significantly associated with morbidity status of under-five children. In the multivariable logistic regression model, we considered all significant variables of the simple logistic regression model and found that children of food-insecure households with improved toilet facility had $53 \%$ (AOR: 1.53; $95 \% \mathrm{Cl} 1.09,2.15)$ more chance, and foodinsecure children with unimproved toilet facility had 5.88 (AOR: $5.88 ; 95 \% \mathrm{Cl} 2.52,13.70$ ) times more 
chance, of being morbid compared to the children of food-secure households with improved toilet facility (Table 3). A similar association of food security and toilet facilities with each of the morbidity components was observed, including diarrhea (AOR:3.6; 95\% Cl 1.79, 7.89), fever (AOR:3.47; 95\% Cl 1.72, 6.99), difficult or fast breathing with cough (AOR:3.88; $95 \% \mathrm{Cl} 1.99,7.59$ ), and difficult or fast breathing with blocked or running nose (AOR:1.29; 95\% Cl 0.56, 2.95) (Fig. 2).

\section{Discussion}

The findings of this study revealed that household FI and unimproved toilet facility have independent effects on child morbidity. However, Fl and unimproved toilet facility combined can have a more severe effect than either alone. These findings have important implications for the development of programmes to alleviate common childhood diseases. Some other studies have reported the association between FI and general health consequences [22-24]; studies also have shown that poor general health, mental and physical health have a relationship with FI $[25,26]$. Studies conducted in Brazil and Colombia found that household FI and child morbidity, such as diarrheal disease among the children, were significantly associated $[3,9]$ corresponding to the findings of our study. However, the interventions or programs taken so far in low- and middle-income countries are vertical and specific to address one particular problem: either FI or child morbidity. Their relationship is often overlooked while designing an intervention. Nevertheless, an integrated program could be cost-effective targeting both improving food security and sanitation status of the households, and, thus, to reduce child morbidity.

It is very likely that the food-insecure households have poor living conditions. The unimproved toilet is one of the dimensions of poor living conditions. Studies indicate that the use of unimproved toilets increases the burden of diseases, like diarrhea among poor children [27, 28]. Our study also found that the children belonging to food-insecure households having unimproved toilet facilities are more likely to suffer from diarrhoea, fever, and fast breathing with cough. Therefore, the study corroborates with the suggested potential nutrition-sensitive interventions such as social protection and safety net program to improve food security and living conditions of the households leading to improvement of child health [29].

Other studies also show that younger children are more susceptible to morbidity when compared to their older counterparts [30]. Apart from household FI and unimproved toilet facility, child's age is also found to be associated with morbidity in our study. Childhood morbidity, particularly diarrheal diseases, are more prevalent among the younger children compared to the older ones [31]. Since child's age is a nonmodifiable factor, the study suggests undertaking of interventions targeting the younger children for reducing morbidity, irrespective of household food security and living conditions.

\section{Limitations and strengths}

Being a community-based study; the participation rate was considerably high as the respondents were at the households during the day of the interview. The survey was cross-sectional and, so, it was difficult to assess the causality between the outcome and exposure variables. Morbidity assessments were self- 
reported by children caregivers through recall of the preceding two weeks from the date of the interview; so, there was a possibility of recall bias. FI data were collected through recall, and the situation prevailed in the past 30 days. The accuracy of data depended on the respondent's memory and honesty. To overcome this, the interviewers were given special training to increase the ability to understand the questions to be asked to the respondents. Self-reported family income and expenditure could also be subject to bias.

\section{Conclusions}

Our study shows that household FI and unimproved toilet facility jointly have more deteriorative effects on child morbidity than either of these conditions alone. Unlike other studies, this illustrates the independent and combined effects of household FI and unimproved toilet facility on child morbidity. Taking measures on food security at the household level may not be sufficient to develop the nutritional status of children, rather an integrated programme on food security and sanitation is recommended to improve the overall health outcomes of the children. This evidence could show the pathway for the implementers and policy-makers that intervention targeting the improvement of the health status of children should not only consider the food security status of the households but also the sanitation condition of the households.

\section{Abbreviations}

FI Food insecurity

MIYCN Maternal, Infant and Young Child Nutrition

AOR Adjusted odds ratios

BRAC Bangladesh Rural Advancement Committee

PSU Primary Sampling Units

HFIAS Household Food Insecurity Access Scale

FANTA Food and Nutrition Technical Assistance

BDT Bangladeshi taka

\section{Declarations}

\section{Ethics approval and consent to participate}

This study was approved by the IRB of icddr,b which comprises a Research Review Committee and an Ethical Review Committee (Protocol number PR-14048). Written consents were taken from all caregivers 
before taking any interview. The participants were informed by the interviewer that their participation is voluntary and they have the right not to answer any question or to withdraw themselves any time during the interview.

\section{Consent for publication}

Not applicable.

\section{Availability of data and materials}

The data that support the findings of this study are available from corresponding author (HS) upon reasonable request and with permission of icddr,b IRB.

\section{Competing interests}

The authors declare that they have no competing interests

\section{Funding}

Research for this article was funded by the Children's Investment Fund Foundation (CIFF), UK. The views, opinions, assumptions, or any other information set out in this article are solely those of the authors and should not be attributed to CIFF or any person connected with CIFF.

\section{Authors' contributions}

M.A.I. and H.S. conceptualized the paper. M.A.I., M.T., M.R., H.S., and G.K. engaged in formal analysis. M.A.I., M.R., M.F.U., and H.S. prepared the first draft. M.A.R., M.K., D.G., and T.A. critically reviewed and provided technical feedback on the draft version of the paper. H.S. rewrite and finalized the paper considering review comments from all authors. All authors reviewed and approved the final version of the paper.

\section{Acknowledgements}

All authors and icddr,b acknowledge with gratitude the commitment of CIFF to its research efforts; icddr,b is also grateful to the core donors: the Governments of the People's Republic of Bangladesh, Canada, Sweden, and the UK for providing core/unrestricted support. The authors thank BRAC and GAIN for their assistance in conducting the study and the study participants for their participation and giving their 
valuable time. The authors also thank all members of the research team who helped during data collection.

\section{References}

1. Napoli, M., Muro, P. De \& Mazziotta, M. Towards a food insecurity Multidimensional Index (FIMI). Romatre: Universita Degli Studi. 2011. http://www.fao.org/fileadmin/templates/ERP/uni/FIMI.pdf. Last accessed on 22 August 2021.

2. Norhasmah S, Zalilah MS, Mohd Nasir MT, Kandiah M, Asnarulkhadi AS. A Qualitative Study on Coping Strategies among Women from Food Insecurity Households in Selangor and Negeri Sembilan. Malays J Nutr, 2010;16(1), 39-54.

3. FAO, IFAD, UNICEF, WFP and WHO. The State of Food Security and Nutrition in the World 2017. Building resilience for peace and food security. Rome, FAO. 2017. https://www.unicef.org/media/49031/file/State_of_Food_Security_and_Nutrition_in_the_World_2017ENG.pdf. Last accessed on 22 August 2021.

4. USAID. 2019, May 21. Agriculture And Food Security. accesssed https://www.usaid.gov/bangladesh/agriculture-and-food-security

5. Global Food Security Index (2017). Report from Economist Intelligence Unit. Retrieved from: https://foodsecurityindex.eiu.com/Home/DownloadResource? fileName=EIU\%20Global\%20Food\%20Security\%20Index\%20\%202017\%20Findings\%20\%26\%20Methodology.pdf. Last accessed 22 August 2021.

6. Haque MA, Farzana FD, Sultana S, Raihan MJ, Rahman AS, Waid JL. Factors associated with child hunger among food insecure households in Bangladesh. BMC Public Health. 2017;17 (1):205.

7. Kirkpatrick SI, Mclntyre L, Potestio ML. Child hunger and long-term adverse consequences for health. Arch Pediatr Adolesc Med. 2010;164(8):754-62.

8. Anderson LC, Tegegn A, Tessema F, Galea S, Hadley C. Food insecurity, childhood illness and maternal emotional distress in Ethiopia. Public Health Nutr. 2011;15(4):648-55.

9. Gubert MB, Spaniol AM, Bortolini GA, Pérez-Escamilla R. Household food insecurity, nutritional status and morbidity in Brazilian children. Public Health Nutr. 2016;19(12):2240-5.

10. Ohemeng A, Marquis GS, Lartey A. Household Food Insecurity is Associated with Respiratory Infections Among 6-11-Month Old Infants in Rural Ghana. Pediatr Infect Dis J. 2015;34(8):821-5.

11. Chilton M, Rose D. A rights-based approach to food insecurity in the United States. Am. J. Public Health. 2009;99(7):1203-11.

12. Sarma H, Khan JR, Asaduzzaman M, Uddin F, Tarannum S, Hasan MM, Rahman AS, Ahmed T. Factors Influencing the Prevalence of Stunting Among Children Aged Below Five Years in Bangladesh. Food Nutr Bull. 2017;38(3): p. 291-301.

13. Ali D, Saha KK, Nguyen PH, Diressie MT, Ruel MT, Menon P, Rawat R. Household food insecurity is associated with higher child undernutrition in Bangladesh, Ethiopia, and Vietnam, but the effect is not 
mediated by child dietary diversity. J Nutr. 2013;143(12):2015-21.

14. Iram U, Muhammad S, Butt. Determinants of household food security: An empirical analysis for Pakistan, Int J Soc Econ. 2004;31: 8,753-766. https://doi.org/10.1108/03068290410546011

15. National Institute of Population Research and Training (NIPORT). Bangladesh demographic and health survey 2017-18: Key indicators. https://dhsprogram.com/pubs/pdf/PR104/PR104.pdf. Last accessed on 2 August 2021.

16. Mesagan PE, Adeniji-Ilori OM, Fudan J. Household Environmental Factors and Childhood Morbidity in South-Western Nigeria. Hum Soc Sci. 2018;11:411. https://doi.org/10.1007/s40647-017-0204-9

17. Kumar S, Vollmer S. Does access to improved sanitation reduce childhood diarrhea in rural India?. Health Econ. 2013;22(4):410-42.

18. Ullah MB, Mridha MK, Arnold CD, Matias SL, Khan MS, Siddiqui Z, Hossain M, Paul RR, Dewey KG. Factors associated with diarrhea and acute respiratory infection in children under two years of age in rural Bangladesh. BMC Pediatr. 2019;19(1):1-1.

19. Naz L, Ghimire U. Unimproved water, sanitation, and hygiene (WASH) and common childhood illness in Myanmar: evidence from a nationally representative survey. (2020) https://doi.org/10.21203/rs.3.rs-36037/v1

20. Sarma H, Mbuya MN, Tariqujjaman M, Rahman M, Askari S, Khondker R, Sultana S, Shahin SA, Bossert TJ, Banwell C, Neufeld LM. Role of home visits by volunteer community health workers: to improve the coverage of micronutrient powders in rural Bangladesh. Public Health Nutr. 2021;24(S1):s48-58.

21. Coates J, Swindale A, Bilinsky P. Household food insecurity access scale (HFIAS) for measurement of household food access: Indicator guide (v. 3). Washington, DC: food and nutrition technical assistance project, academy for educational Development. 2007 Aug:1-36. http://www.fao.org/fileadmin/user_upload/eufao-fsi4dm/doc-training/hfias.pdf. Last accessed on 22 August 2021.

22. Stuff JE, Casey PH, Szeto KL, Gossett JM, Robbins JM, et al. Household food insecurity is associated with adult health status. $J$ Nutr. 2004;134(9): 2330-5.

23. Casey PH, Szeto KL, Robbins JM, Stuff JE, Connell C, Gossett JM, et al. Child health-related quality of life and household food security. Arch Pediatr Adolesc Med. 2005;159(1): 51-6.

24. Sharkey JR, Johnson CM, Dean WR. Relationship of household food insecurity to health-related quality of life in a large sample of rural and urban women. Women Health. 2011;51(5):442-60.

25. Huddleston-Casas C, Charnigo R, Simmons LA. Food insecurity and maternal depression in rural, lowincome families: a longitudinal investigation. Pub Health Nutr. 2009;12(8):1133-40.

26. Leung CW, Epel ES, Willett WC, Rimm EB, Laraia BA. Household food insecurity is positively associated with depression among low income supplemental nutrition assistance program participants and income-eligible nonparticipants. J Nutr. 2015;145(3): 622-7.

27. Ohemeng A, Marquis GS, Lartey A. Household Food Insecurity is Associated with Respiratory Infections Among 6-11-Month Old Infants in Rural Ghana. Pediatr Infect Dis J. 2015;34(8):821-5. 
28. Cook JT, Frank DA, Levenson SM, Neault NB, Heeren TC, Black, MM, et al. Child food insecurity increases risks posed by household food insecurity to young children's health. $J$ Nutr. 2006;136(4):1073-6.

29. Bhutta ZA, Das JK, Rizvi A, Gaffey MF, Walker N, Horton S, et al. Evidence-based interventions for improvement of maternal and child nutrition: what can be done and at what cost? Lancet. 2013;382(9890), 452-77. doi:10.1016/s0140-6736(13)60996-4.

30. Kamal MM, Hasan MM, Davey R. Determinants of childhood morbidity in Bangladesh: evidence from the Demographic and Health Survey 2011. BMJ open. 2015;5:e007538. doi: 10.1136/bmjopen-2014007538.

31. Woldemicael G. Diarrhoeal Morbidity among Young Children in Eritrea: Environmental and Socioeconomic Determinants. J Health Popul Nutr. 2001;19(2):83-90.

\section{Figures}




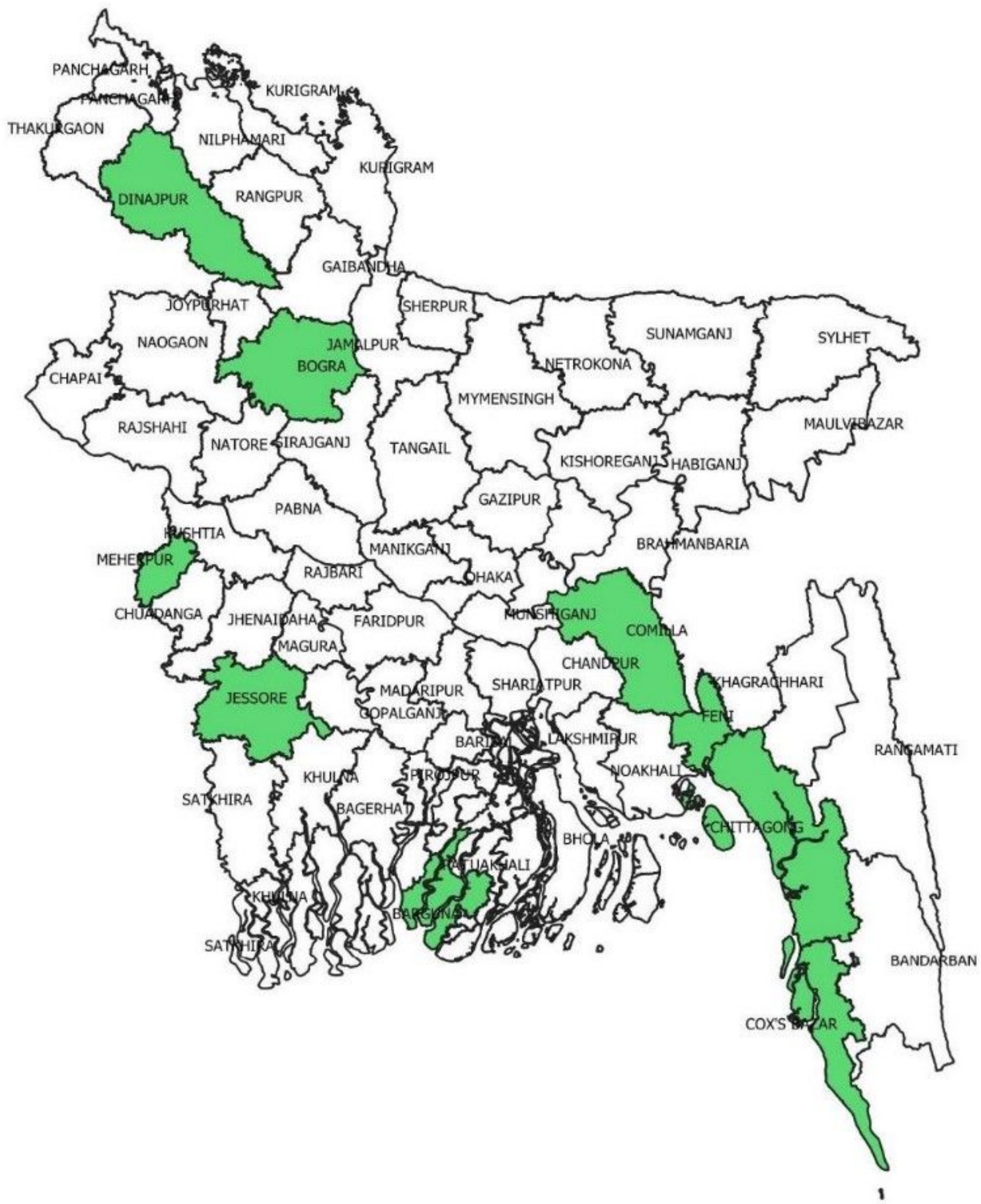

Figure 1

Map of Bangladesh-the highlighted districts indicate the study areas 

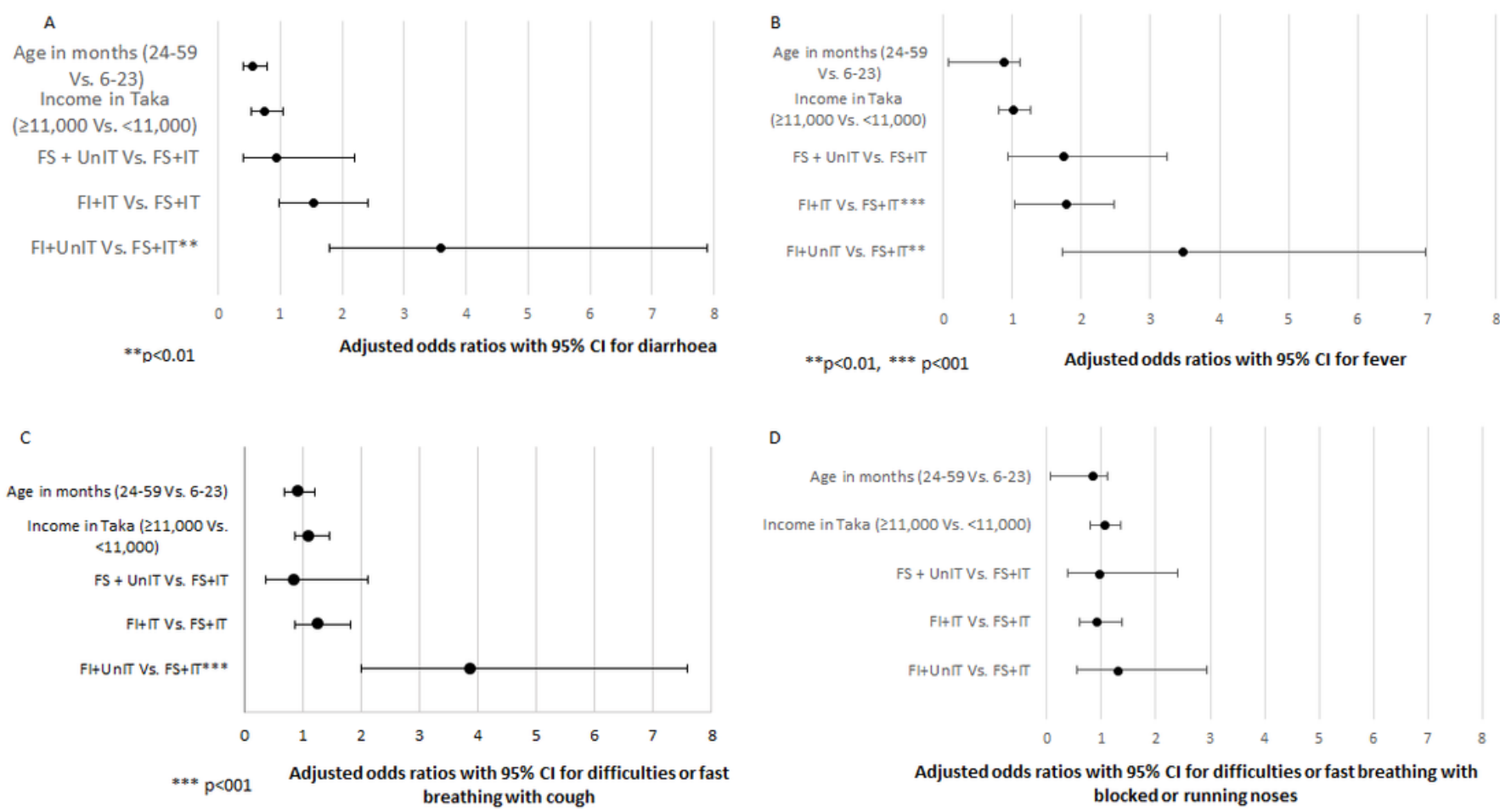

Adjusted odds ratios with $95 \% \mathrm{Cl}$ for difficulties or fast breathing with blocked or running noses

$\mathrm{FS}$ = Food secure; FI = Food insecure; IT = Improved toilet; UnIT = Unimproved toilet

\section{Figure 2}

Household FI and unimproved toilet facilities associated with each of the four morbidity statuses of children

\section{Supplementary Files}

This is a list of supplementary files associated with this preprint. Click to download.

- Additionalfile1.docx 